\title{
Road Cross-Section Width and Free-Flow Speed on Two-Lane Rural Highways
}

\author{
Pedro Melo, António Lobo, António Couto, and Carlos Manuel Rodrigues
}

Speed choice is strongly influenced by geometric road features. In this work, the influence of lane and shoulder widths on free-flow speed was studied with the driving simulator DriS at the University of Porto in Porto, Portugal. To evaluate how speed was influenced by the cross section, this study investigated the possible influence of the order of magnitude of the practiced speeds on the effects of variations in lane and shoulder widths. Two types of roads with different base speeds were considered. The roads were presented to drivers on a driving simulator. The validity of the data obtained in the simulator was confirmed through a comparative analysis of the registered speeds in the real environments for the equivalent simulator conditions at six points of control. The lane and shoulder widths from which the free-flow speed was no longer conditioned by the dimensions of the road's cross section were obtained, as well as the reduction in speed associated with smaller widths. Contrary to what was suggested by the Highway Capacity Manual 2010, the individual effects of variations in lane and shoulder widths were not cumulative; greater impacts on free-flow speed were obtained by their simultaneous variation.

An important component in characterizing the service provided by a given highway is the free-flow speed (1), which represents drivers' speed choice under free-flow conditions. The free-flow speed reflects drivers' response to road geometric and environmental characteristics without the presence of vehicles ahead. The free-flow speed can be also affected by vehicle characteristics and general driving practices. According to the Highway Capacity Manual 2010 (HCM) (1), the level of service for two-lane highways depends on the average travel speed, which in turn depends on the free-flow speed. When it is not possible to conduct the measurements required for calculating the free-flow speed, the HCM (1) proposes an estimation model in which some correction values representing road geometric characteristics are applied to a base free-flow speed. This model is represented by Equation 1:

$\mathrm{FFS}=\mathrm{BFFS}-f_{\mathrm{LS}}-f_{\mathrm{A}}$

where

FFS $=$ free-flow speed,

BFFS $=$ base free-flow speed,

$f_{\mathrm{LS}}=$ adjustment parameter for lane and shoulder width (in kilometers per hour), and

$f_{A}=$ adjustment parameter due to density of access points (in kilometers per hour).

University of Porto, Civil Engineering Department, Transport Infrastructure Division, Rua Dr. Roberto Frias, s/n, 4200-465 Porto, Portugal. Corresponding author: A. Lobo, lobo@fe.up.pt.

Transportation Research Record: Journal of the Transportation Research Board, No. 2301, Transportation Research Board of the National Academies, Washington, D.C., 2012, pp. 28-35.

DOI: $10.3141 / 2301-04$
The base free-flow speed can be assumed as the speed observed for roads presenting the basic requirements of the geometric conditions suggested by the HCM (1): no access points and lane and shoulder widths equal to or greater than $3.6 \mathrm{~m}$ and $1.8 \mathrm{~m}$, respectively. For smaller cross sections and higher densities of access points, the HCM (1) proposes reductions in the free-flow speed. The reductions related to the width of the cross section are presented in Table 1.

Speed reductions presented in the HCM (1) are based on the findings of Harwood et al., presented in the final report of NCHRP Project 3-55(3) (2). In this report, a regression relationship between shoulder width reduction and speed reduction observed in a real environment was performed; it assessed the effects of lane width variation on free-flow speed on the basis of previous studies in the area. The values in Table 1 suggest cumulative effects on the free-flow speed from variations in lane and shoulder width (i.e., the reduction in speed for a given cross section composed of a lane width smaller than $3.6 \mathrm{~m}$ and a shoulder width smaller than $1.8 \mathrm{~m}$ is the sum of the individual effects caused by each variable).

This paper contributes to the evaluation of the effects on the free-flow speed from road cross-section characteristics-lane and shoulder width - through a driving simulation study. The simulated environment allows the assessment of speed reductions for a greater number of cross-section combinations as well as the consideration of a wider range of lane width values than the methodology used in NCHRP Project 3-55(3) (2). In addition, the smallest cross section from which the speed choice is no longer affected by the lane and shoulder widths is provided and compared with the HCM (1) proposals.

The establishment of free-flow conditions is defined by the time interval between two successive vehicles. The HCM (1) suggests that a 3-s headway is suitable for free-flow conditions, although this value is not unanimous among the literature. For example, a study of Portuguese two-lane rural roads by Lobo et al. (3) suggests a 6-s gap as the reference for free-flow conditions.

This study contributes to the knowledge of adequate cross-section characteristics for the desired speed of a given road. Several studies on road safety have referred to speeding as a major cause of car accidents $(4,5)$. Therefore, the road geometric features (the horizontal and vertical alignments and cross sections) should suggest to drivers an adequate speed choice to promote road safety and the sustainability of the surrounding environment.

\section{DATA COLLECTION}

\section{Experimental Approach}

Studies of speed can be performed with different methodologies, such as the use of instrumented vehicles, naturalistic studies, real environment monitoring, or driving simulation, depending on the variables to be considered. 
TABLE 1 Adjustment Factor for Reductions in Free-Flow Speed (km/h) According to Lane and Shoulder Widths (1)

\begin{tabular}{lcccc}
\hline \multicolumn{5}{c}{ Shoulder Width $(\mathrm{m})$} \\
\cline { 2 - 5 } Lane Width (m) & $\geq 0.0$ to $<0.6$ & $\geq 0.6$ to $<1.2$ & $\geq 1.2$ to $<1.8$ & $\geq 1.8$ \\
\hline 2.7 to $<3.0$ & 10.3 & 7.7 & 5.6 & 3.5 \\
$\geq 3.0$ to $<3.3$ & 8.5 & 5.9 & 3.8 & 1.7 \\
$\geq 3.3$ to $<3.6$ & 7.5 & 4.9 & 2.8 & 0.7 \\
$\geq 3.6$ & 6.8 & 4.2 & 2.1 & 0.0 \\
\hline
\end{tabular}

This study analyzed the average travel speed adopted for a set of road scenarios with different cross sections. The use of a driving simulator allowed a high level of control over the variables (6). Therefore, it is the most suitable approach for studying changes in drivers' speed choice as a result of the variation of the characteristics of the cross section.

The simulator used in this study was the DriS, which is a fixed-base driving simulator installed at the Traffic Analysis Laboratory of the Faculty of Engineering of the University of Porto in Porto, Portugal. Two roads near Porto (N 105-2 and N 222) were selected for this study. The design speeds of these roads are $40 \mathrm{~km} / \mathrm{h}$ and $80 \mathrm{~km} / \mathrm{h}$, respectively, representing two types of roads: one more winding and the other less demanding for drivers. For each road, the road alignment of a 3-km-long section was collected by a Global Positioning System device installed in an instrumented vehicle. Then, both stretches were reproduced in the DriS to compare the influence of variations in the cross-section width on the free-flow speed of roads presenting different alignment standards. It was expected that the effects of the characteristics of the cross section were greater for higher speeds.

The driving experiences conducted in the DriS were performed by 15 drivers. The group of drivers had the following characteristics: (a) $60 \%$ were males and $40 \%$ were females; (b) they ranged in age from 20 to 40 years; $(c)$ each driver had held a driver's license for 3 or more years; $(d)$ each driver drove at least $10,000 \mathrm{~km}$ per year, with $5,000 \mathrm{~km}$ on two-lane rural highways; and $(e)$ they did not usually drive on the chosen roads. The 15 drivers were selected because they adapted well to the simulated environment and showed realistic driving behaviors.

The drivers drove the DriS across the simulated roads, composed of successive 3-km-long sections, each one presenting a different combination of lane and shoulder width. The characteristics of the horizontal alignment were kept the same. Smooth cross-section transitions between scenarios were ensured by intermediate 100-m-long tangent sections. The lane and shoulder widths are presented in Table 2.

The values considered for lane and shoulder widths were chosen according to the HCM (1) (Table 1) and according to the crosssection characteristics most commonly adopted on these types of roads. For each road, the 16 scenarios were driven in sequences of four to avoid driver fatigue. These sequences were chosen randomly to avoid excessive familiarity with the road alignment, and they were preceded by $5-\mathrm{km}$-long training stretches.

The realism of the simulated environment was improved through the introduction of trees at the roadside and of opposing traffic appearing in the same spot of the road for all the scenarios. The presence
TABLE 2 Cross-Section Scenarios Presented in Simulated Environment

\begin{tabular}{|c|c|c|c|c|c|c|c|c|}
\hline \multirow{3}{*}{$\begin{array}{l}\text { Lane } \\
\text { Width (m) }\end{array}$} & \multicolumn{8}{|c|}{ Shoulder Width (m) } \\
\hline & \multicolumn{4}{|c|}{ N 105-2 } & \multicolumn{4}{|c|}{ N 222} \\
\hline & 0.3 & 0.8 & 1.2 & 1.8 & 1.2 & 1.8 & 2.2 & 2.5 \\
\hline 2.7 & 9 & 8 & 10 & 12 & 9 & 8 & 10 & 12 \\
\hline 3.0 & $\begin{array}{c}7 \\
\text { (II; III) }\end{array}$ & 1 & 2 & 11 & 7 & 1 & 2 & 11 \\
\hline 3.3 & 4 & $3(\mathrm{I})$ & 13 & 15 & 4 & 3 & 13 & 15 \\
\hline 3.6 & 6 & 5 & 16 & 14 & 6 & 5 & $\begin{array}{c}16 \\
(\mathrm{I} ; \mathrm{II})\end{array}$ & $\begin{array}{c}14 \\
\text { (III) }\end{array}$ \\
\hline
\end{tabular}

NotE: Observations I, II, and III-cross sections considered for validation with the real environment spot speeds.

of vehicles ahead was not introduced in the simulated environment. In these conditions, the average travel speed corresponds to the free-flow speed.

The selected 3-km-long stretches were built on level terrain, with grades below $3 \%(1)$. Therefore, the effects of the vertical alignment were not considered in the simulator study. Moreover, no intersections, which could disturb drivers' speed choice, were present in the road sections under consideration.

In Figure 1, the simulation setting and screen are presented.

\section{Description of Variables}

The variables considered in this study were evaluated using the vehicle's spatial and temporal location, collected by the DriS.

First, a set of three variables was considered to evaluate the quality of each experiment, removing drivers who had adopted unrealistic behaviors. Thus, using the registered number of times that drivers crossed the lane limits, two variables were created: the average percentage of road length driven crossing the centerline and the average percentage of the road length driven crossing the sideline. These variables are mutually exclusive, and their sum represents the average percentage of road length driven out of the lane limits. For both roads, the maximum driving error allowed for the drivers was approximately $30 \%$.

The average distance to the centerline and the average distance to the sideline were estimated for a sensitivity analysis of the driver's behavior when faced with different cross-section widths. For this estimation, the distances registered out of lane limits were considered to be negative.

For the development of the regression model, the dependent variable was the free-flow speed obtained in the simulated environment, which is represented by the average travel speed estimated for each cross-section combination, with the length of the stretch divided by the average travel time observed for each driver.

The independent variables were lane width, shoulder width, the product of the lane and shoulder widths, and the dummy variables representing the different roads and drivers. The product of the lane and shoulder widths allowed the evaluation of the combined effects of both variables. The dummy variables for the roads allowed the inclusion of all gathered data into the same regression, increasing the number of observations. Otherwise, some combinations of lane 


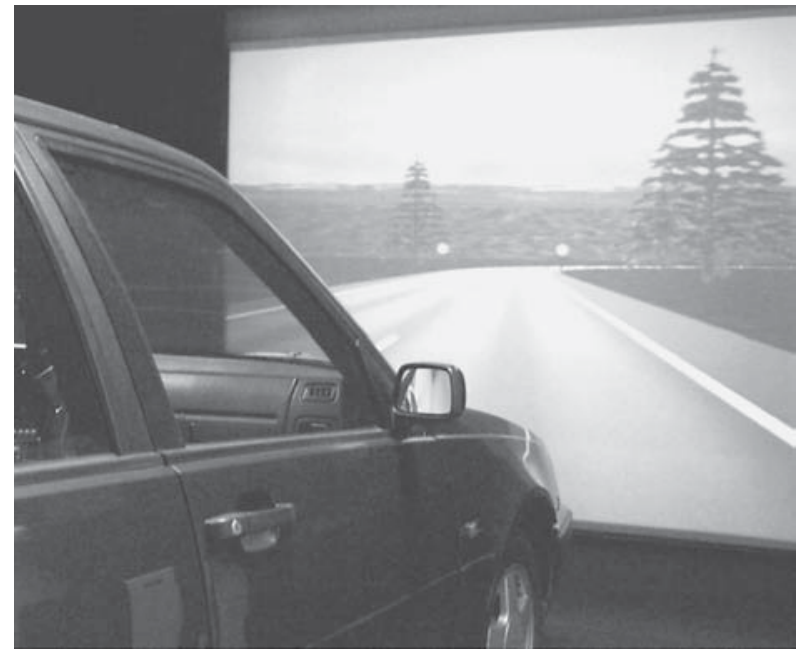

(a)

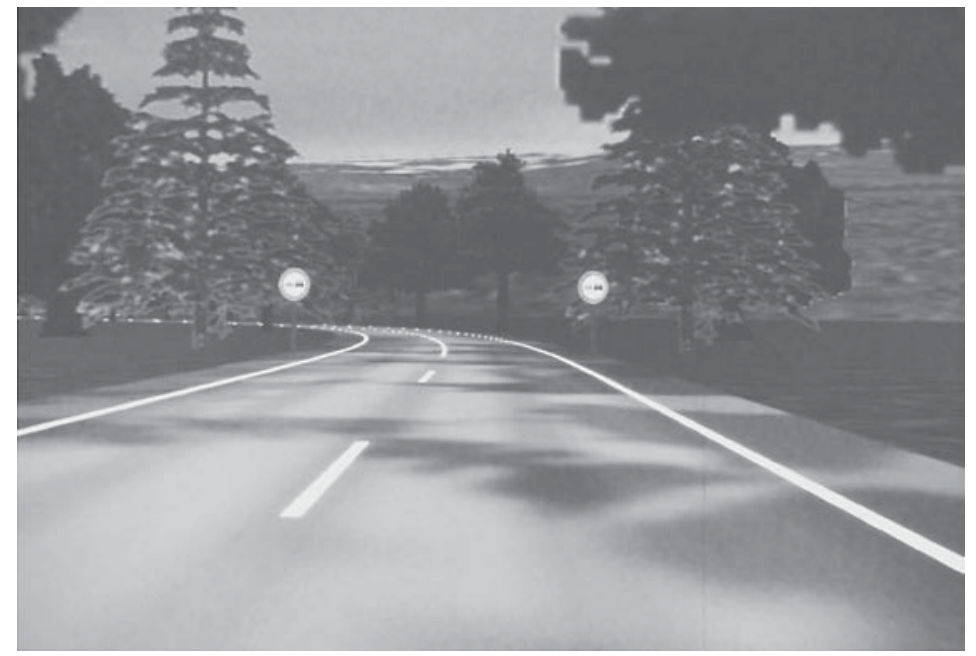

(b)

FIGURE 1 DriS simulation setting and screen.

and shoulder widths would be repeated without being distinguished by the road type. Dummy variables related to drivers express the individual driving behavior observed for each person when compared with a randomly chosen base driver. Thus, only 14 dummy variables for the drivers were considered.

Finally, the speed values obtained in the simulated environment were calibrated. Therefore, the average spot speed in the real environment was determined for three elements (tangents and curves) of each road. The same speed was then determined in the simulated environment for the same elements (with the same cross-section width), allowing the comparison between both environments.

\section{METHODOLOGY PROPOSED}

\section{Regression Modeling}

The proposed model assumes that the relationship between the free-flow speed and the independent variables is suitable to be represented by a power function that can be linearized by extracting the natural logarithm of the continuous variables, as presented in Equation 2:

$$
\ln (\mathrm{FFS})=a+b \ln (l)+c \ln (s)+d \ln (l) \ln (s)+e d_{r}+\sum_{i=1}^{14} f_{i} d_{d i}
$$

where

$$
\text { FFS }=\text { free-flow speed, }
$$

$a, b, c, d, e, f_{i}=$ regression coefficients,

$l=$ lane width

$s=$ shoulder width,

$d_{r}=$ dummy variable for road type, and

$d_{d i}=$ dummy variable for drivers.

A multiple linear regression (the least squares approach) was performed with Equation 2 to estimate the effects of the cross section on the free-flow speed.
Then, for each cross-section width and road type, the average free-flow speed value of the 15 drivers was estimated. The minimum cross section from which the increase in lane and shoulder widths did not produce effects on the free-flow speed was considered the baseline scenario. This scenario serves as a reference for estimating the reductions in the free-flow speed for the geometric characteristics of narrower cross sections.

\section{Validation of Results}

The road sections tested in the simulated environment were reproductions of real roads, allowing the results obtained in the simulator to be validated (7). The validation was performed through a comparative analysis of the spot speeds observed in the real and simulated environments at six points of control (represented in Table 2 by the numerals I, II, and III for each road).

In the simulated environment, spot speeds were automatically registered by the DriS. In the real environment, spot speeds were collected with traffic-counting devices, consisting of a Doppler radar sensor with integrated flash random access memory and a real-time clock. These devices were placed at approximately a half-extension of the road elements used for the validation. The presence of the traffic counters was disguised to avoid biasing driver behavior.

The vehicles used for the free-flow speed estimation in the real environment presented headways equal to or greater than $10 \mathrm{~s}$ to ensure free-flow travel conditions.

\section{APPLICATION PERFORMED}

\section{Variable Estimation}

The experimental study was performed in the DriS, and the variables were obtained for each driver. In Tables 3 and 4, the average variable values for the entire set of drivers are presented for each road and cross section under consideration. As expected, higher speeds were practiced on the road with a less demanding horizontal alignment. 


\section{Vehicle Positioning in Cross Section}

In Figure 2, the variation in the average distance to the sideline with the cross-section width is presented. The reference values for the distance to sideline, established for a vehicle traveling at the center of the lane, are represented by the dashed line.

For large cross-section widths, drivers tended to travel closer to the sideline because of higher horizontal clearances caused by the increase in shoulder width. As the lane and shoulder width decreased, drivers tended to move toward the centerline to attempt to maintain the same speed, holding the distance to the objects on the roadside. As a consequence of the smaller distance to the opposing traffic stream, drivers tended to reduce speed in the presence of oncoming vehicles.

\section{Multivariate Analysis}

To evaluate the effects of the lane and shoulder widths of both road types on the free-flow speed, a multivariate linear regression using Equation 2 was performed with the data collected in the simulated environment. The model was conducted using the statistical software for econometric analysis Limdep (8). The regression coefficients and corresponding $P$-values for the set of considered variables are presented in Table 5.

The majority of the considered variables are statistically significant at a $10 \%$ level. The exceptions were Driver 1 and four dummy variables. However, the corresponding coefficients were nearly zero, revealing that the behavior of these drivers was similar to that of the base driver.

The speed practiced by the most aggressive driver was around $30 \%$ higher than the speed adopted by the least aggressive driver.

The goodness of fit was evaluated with the correlation coefficient ( $R=0.89$ ). According to Cohen (9), a coefficient value above 0.5 represents large correlations between the variables. The coefficient of determination $\left(R^{2}\right)$ expresses that $79 \%$ of free-flow speed variance is explained by the variance of the independent variables.

For the road with the lower design speed $\left(d_{r}=0\right)$, the free-flow speed was obtained for each cross section by averaging the free-flow speed practiced by the 15 drivers. The same procedure was adopted for the road with the higher design speed $\left(d_{r}=1\right)$.

The Kolmogorov-Smirnov test was performed for the 32 samples of the 15 speed values obtained in each cross section. Each sample was accepted as being normally distributed for a significance level of 5\%, ensuring that the average speed value was representative of the sample.

The elasticities at the sample mean were $0.12 \%$ for lane width and $0.025 \%$ for shoulder width. These values represent the increase in free-flow speed caused by a $1 \%$ increase in lane or shoulder width. However, it is more important to observe the variations in speed produced by different combinations of lane and shoulder widths than to analyze the effects at the sample mean. Thus, Equation 2 was applied to diverse combinations of cross sections. The speed reduction results are presented in Table 6.

Some observations arise from a comparison of Table 1 and Table 6. First, the baseline scenario, corresponding to the minimum cross section, above which significant variations on free-flow speed $(<0.5 \mathrm{~km} / \mathrm{h})$ are no longer observed, is established in this study for a lane $3.6 \mathrm{~m}$ wide combined with a shoulder $0.8 \mathrm{~m}$ wide. These baseline widths are valid for both of the studied road types. For wider cross sections, the free-flow speed was strongly influenced by geometric characteristics other than lane and shoulder widths. The base cross section proposed by the $\mathrm{HCM}(1)$ is formed by a lane $3.6 \mathrm{~m}$ wide and a shoulder $1.8 \mathrm{~m}$ wide. Because this reference manual was developed for North American conditions, where vehicles are generally wider than in Europe, the minimum cross section not influencing the free-flow speed was expected to be smaller in Portugal.

It is also possible to confirm that narrower cross sections produce greater effects on the free-flow speed. These effects were gradually reduced with increases in lane and shoulder widths. This study obtained values of speed reduction that were different from those of the HCM (1). The speed reductions proposed in Table 1 for narrower cross sections are proportional to those found in Table 6 for the less demanding road (N 222). Moreover, despite the differences in the baseline scenario between this study and the HCM (1), the speed reduction for the narrowest cross section observed at $\mathrm{N} 222$ was close to the value proposed by the HCM (1): approximately $10 \mathrm{~km} / \mathrm{h}$.

The geometric characteristics of the road with a lower design speed (N 105-2) were significantly different from the characteristics of the roads considered by the HCM (1). The HCM considers two-lane highways with operating speeds between 70 and $110 \mathrm{~km} / \mathrm{h}$. However, the comparison of the two roads shows that the effects of the width of the cross section on the free-flow speed depend on the range of speed. The average travel speed observed in the DriS for N 105-2 was approximately $68 \%$ of the speed for $\mathrm{N} 222$. This proportion is approximately the same observed for the speed reductions between both roads for each lane and shoulder width combination.

Another important conclusion from Table 6 is that the effects caused by variations in lane and shoulder widths were not cumulative: the speed reduction for a combined lane and shoulder decrease was higher than the sum of the speed reductions caused by the correspondent decreases in lane and shoulder widths individually. Marginal effects of lane and shoulder width on speed may be obtained through deriving the regression function (Equation 2) with respect to the shoulder $[\ln (s)]$ or lane $[\ln (l)]$ widths.

For example, in Table 6, it is possible to observe that the reduction in shoulder width from $0.8 \mathrm{~m}$ to $0.3 \mathrm{~m}$ varies according to the lane width. Likewise, the decrease in lane width from $3.6 \mathrm{~m}$ to $2.7 \mathrm{~m}$ depends on the shoulder's variation.

Conversely, the HCM (1) does not reflect different reductions in the free-flow speed from a combined lane and shoulder decrease or the sum of the correspondent individual effects (i.e., the speed reductions between two successive intervals of lane width presented in Table 1 are independent of shoulder width and vice versa).

\section{Spot Speed Comparison Between Simulated and Real Environments}

To validate the results from the driving simulator, a comparative analysis of spot speeds measured in the simulated and real environments was performed. For each of the six points of control, the average spot speeds in the real environment $\left(\mathrm{SS}_{r}\right)$ and the simulated environment $\left(\mathrm{SS}_{s}\right)$, the corresponding difference $\left(\mathrm{SS}_{s}-\mathrm{SS}_{r}\right)$, and the standard deviations $\left(\mathrm{SD}_{r}\right.$ and $\left.\mathrm{SD}_{s}\right)$ were evaluated. The sample size in the real environment $\left(N_{r}\right)$ depended on the traffic passing at each point of control. In the simulated environment, the sample size $\left(N_{s}\right)$ was formed by the 15 drivers of the DriS.

Table 7 presents the variables used for comparing the spot speeds between the real and simulated environments. The radii and extensions of the road sections containing the points of control are also presented. 
TABLE 3 Mean Values Collected for N 105-2

\begin{tabular}{|c|c|c|c|c|c|c|c|c|}
\hline & \multicolumn{8}{|l|}{ Scenario } \\
\hline & 1 & 2 & 3 & 4 & 5 & 6 & 7 & 8 \\
\hline Lane width (m) & 3 & 3 & 3.3 & 3.3 & 3.6 & 3.6 & 3 & 2.7 \\
\hline Shoulder width (m) & 0.8 & 1.2 & 0.8 & 0.3 & 0.8 & 0.3 & 0.3 & 0.8 \\
\hline Platform width (m) & $2 \times 3.8$ & $2 \times 4.2$ & $2 \times 4.1$ & $2 \times 3.6$ & $2 \times 4.4$ & $2 \times 3.9$ & $2 \times 3.3$ & $2 \times 3.5$ \\
\hline Average travel speed $(\mathrm{km} / \mathrm{h})$ & 67.4 & 71.1 & 72.9 & 73.8 & 71.3 & 76.0 & 73.9 & 73.6 \\
\hline \multicolumn{9}{|l|}{ Number of errors } \\
\hline Centerline & 7 & 6 & 5 & 5 & 3 & 3 & 5 & 7 \\
\hline Sideline & 10 & 11 & 13 & 13 & 3 & 3 & 1 & 0 \\
\hline Total & 17 & 17 & 18 & 17 & 6 & 6 & 6 & 7 \\
\hline \multicolumn{9}{|l|}{$\%$ errors } \\
\hline Centerline & 6.7 & 5.3 & 4.44 & 4.7 & 1.7 & 1.8 & 5.1 & 6.0 \\
\hline Sideline & 13.1 & 12.7 & 18.9 & 19.0 & 2.1 & 2.6 & 0.4 & 0.0 \\
\hline Total & 19.8 & 18.0 & 23.3 & 23.6 & 3.7 & 4.4 & 5.4 & 6.0 \\
\hline \multicolumn{9}{|l|}{ Average distance (m) } \\
\hline Centerline & 0.6 & 0.63 & 0.71 & 0.70 & 0.83 & 0.83 & 0.58 & 0.48 \\
\hline Sideline & 0.49 & 0.46 & 0.38 & 0.38 & 0.86 & 0.85 & 1.10 & 1.20 \\
\hline
\end{tabular}

TABLE 4 Mean Values Collected for N 222

\begin{tabular}{|c|c|c|c|c|c|c|c|c|}
\hline & \multicolumn{8}{|l|}{ Scenario } \\
\hline & 1 & 2 & 3 & 4 & 5 & 6 & 7 & 8 \\
\hline Lane width (m) & 3 & 3 & 3.3 & 3.3 & 3.6 & 3.6 & 3 & 2.7 \\
\hline Shoulder width (m) & 1.8 & 2.2 & 1.8 & 1.2 & 1.8 & 1.2 & 1.2 & 1.8 \\
\hline Platform width (m) & $2 \times 4.8$ & $2 \times 5.2$ & $2 \times 5.1$ & $2 \times 4.5$ & $2 \times 5.4$ & $2 \times 4.8$ & $2 \times 4.2$ & $2 \times 4.5$ \\
\hline Average travel speed $(\mathrm{km} / \mathrm{h})$ & 106.4 & 118.3 & 121.7 & 123.2 & 105.80 & 116.4 & 115.9 & 116.2 \\
\hline \multicolumn{9}{|l|}{ Number of errors } \\
\hline Centerline & 1 & 1 & 1 & 1 & 1 & 1 & 1 & 2 \\
\hline Sideline & 4 & 2 & 6 & 4 & 1 & 1 & 0 & 0 \\
\hline Total & 5 & 3 & 7 & 5 & 2 & 2 & 1 & 2 \\
\hline \multicolumn{9}{|l|}{$\%$ errors } \\
\hline Centerline & 1.3 & 1.8 & 1.5 & 1.7 & 1.0 & 0.8 & 1.2 & 3.7 \\
\hline Sideline & 7.4 & 6.1 & 18.2 & 15.6 & 2.1 & 3.0 & 0.9 & 0.0 \\
\hline Total & 8.7 & 8.0 & 19.7 & 17.4 & 3.1 & 3.9 & 2.0 & 3.7 \\
\hline \multicolumn{9}{|l|}{ Average distance $(\mathrm{m})$} \\
\hline Centerline & 0.62 & 0.61 & 0.75 & 0.72 & 0.90 & 0.89 & 0.65 & 0.50 \\
\hline Sideline & 0.45 & 0.46 & 0.31 & 0.35 & 0.79 & 0.79 & 1.04 & 1.19 \\
\hline
\end{tabular}




\begin{tabular}{|c|c|c|c|c|c|c|c|}
\hline 9 & 10 & 11 & 12 & 13 & 14 & 15 & 16 \\
\hline 2.7 & 2.7 & 3 & 2.7 & 3.3 & 3.6 & 3.3 & 3.6 \\
\hline 0.3 & 1.2 & 1.8 & 1.8 & 1.2 & 1.8 & 1.8 & 1.2 \\
\hline $2 \times 3$ & $2 \times 3.9$ & $2 \times 4.8$ & $2 \times 4.5$ & $2 \times 4.5$ & $2 \times 5.4$ & $2 \times 5.1$ & $2 \times 4.8$ \\
\hline 71.3 & 74.5 & 77.6 & 76.8 & 75.8 & 79.8 & 79.4 & 79.0 \\
\hline 5 & 6 & 3 & 5 & 2 & 1 & 2 & 1 \\
\hline 10 & 12 & 19 & 13 & 5 & 8 & 5 & 8 \\
\hline 15 & 18 & 22 & 19 & 7 & 9 & 7 & 9 \\
\hline 5.4 & 4.5 & 2.4 & 4.2 & 1.4 & 1.2 & 1.8 & 1.3 \\
\hline 10.6 & 13.7 & 29.2 & 13.6 & 4.5 & 10.6 & 6.0 & 9.9 \\
\hline 16.1 & 18.2 & 31.6 & 17.7 & 5.9 & 11.8 & 7.8 & 11.2 \\
\hline 0.47 & 0.49 & 0.63 & 0.50 & 0.77 & 0.89 & 0.77 & 0.88 \\
\hline 0.32 & 0.30 & 0.16 & 0.29 & 0.61 & 0.50 & 0.62 & 0.51 \\
\hline
\end{tabular}

9

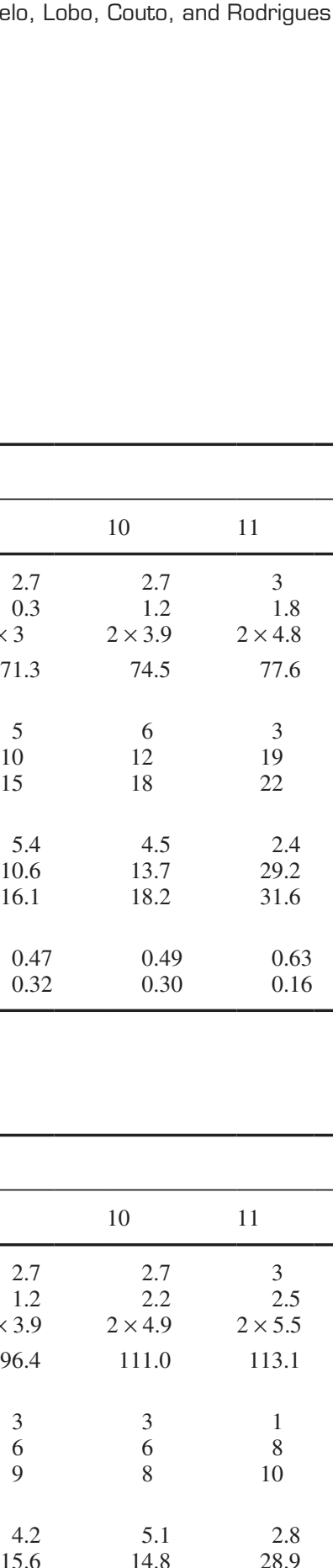

\begin{tabular}{|c|c|c|}
\hline & 10 & 11 \\
\hline 2.7 & 2.7 & 3 \\
\hline 0.3 & 1.2 & 1.8 \\
\hline$\times 3$ & $2 \times 3.9$ & $2 \times 4.8$ \\
\hline 71.3 & 74.5 & 77.6 \\
\hline 5 & 6 & 3 \\
\hline 10 & 12 & 19 \\
\hline 15 & 18 & 22 \\
\hline 5.4 & 4.5 & 2.4 \\
\hline 10.6 & 13.7 & 29.2 \\
\hline 16.1 & 18.2 & 31.6 \\
\hline 0.47 & 0.49 & 0.63 \\
\hline 0.32 & 0.30 & 0.16 \\
\hline & 10 & 11 \\
\hline 2.7 & 2.7 & 3 \\
\hline 1.2 & 2.2 & 2.5 \\
\hline$\times 3.9$ & $2 \times 4.9$ & $2 \times 5.5$ \\
\hline 96.4 & 111.0 & 113.1 \\
\hline 3 & 3 & 1 \\
\hline 6 & 6 & 8 \\
\hline 9 & 8 & 10 \\
\hline 4.2 & 5.1 & 2.8 \\
\hline 15.6 & 14.8 & 28.9 \\
\hline
\end{tabular}

$2 \times 3.9 \quad 2 \times 4.9$

$96.4 \quad 111.0$

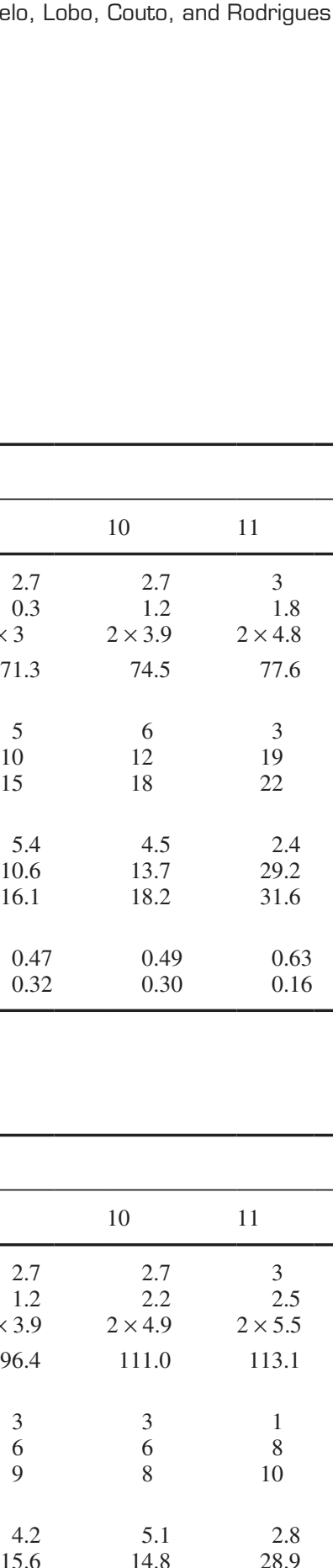

\begin{tabular}{rrrrrrrr}
4.2 & 5.1 & 2.8 & 5.5 & 1.8 & 1.2 & 1.5 & 1.6 \\
15.6 & 14.8 & 28.9 & 14.7 & 7.2 & 13.4 & 3.3 & 11.5 \\
19.9 & 19.9 & 31.8 & 20.2 & 9.0 & 14.7 & 4.9 & 13.1 \\
& & & & & & & \\
0.47 & 0.47 & 0.60 & 0.46 & 0.75 & 0.88 & 0.71 & 0.82 \\
0.29 & 0.30 & 0.16 & 0.30 & 0.62 & 0.48 & 0.65 & 0.54 \\
\hline
\end{tabular}

$12 \quad 13 \quad 14$

$14 \quad 15$

$\begin{array}{rcrrr}2.7 & 3.3 & 3.6 & 3.3 & 3.6 \\ 2.5 & 2.2 & 2.5 & 2.5 & 2.2 \\ 2 \times 5.2 & 2 \times 5.5 & 2 \times 6.1 & 2 \times 5.8 & 2 \times 5.8 \\ 116.1 & 95.9 & 111.4 & 113.6 & 116.5\end{array}$

$\begin{array}{lllll}4 & 1 & 1 & 1 & 1 \\ 5 & 2 & 4 & 2 & 4 \\ 8 & 3 & 5 & 3 & 5\end{array}$




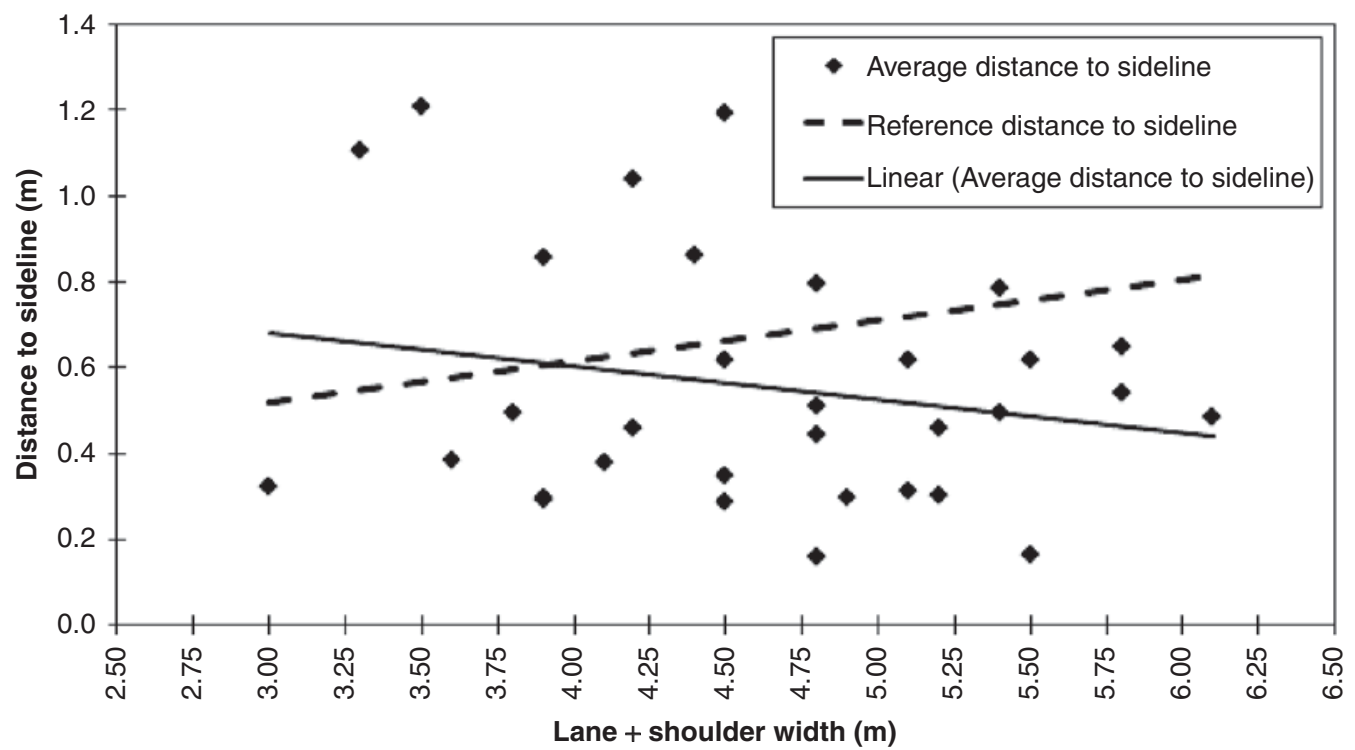

FIGURE 2 Average distance to sideline for different platform widths.

Despite the sample size differences between the real and simulated environments, the statistical dispersion observed for $\mathrm{SS}_{r}$ and $\mathrm{SS}_{s}$ is reasonably similar. On N 222, where characteristics other than geometry can produce higher effects on traffic flow, speed dispersion was smaller for the real environment. On N 105-2, where drivers are strongly conditioned by the geometry of the horizontal alignment, the differences in speed dispersion tended to be smaller.

For each point of control, the samples obtained in both the real and simulated environments were considered as normally distributed samples for a significance level of 5\% through the Kolmogorov-Smirnov test, revealing similarities in drivers' behavior.

TABLE 5 Coefficients of Multiple Linear Regression

\begin{tabular}{lcc}
\hline Variable & Coefficient & $P$-Value \\
\hline Constant & 4.455 & .000 \\
Cross section & & \\
$\quad$ Lane width $(l)$ & 0.143 & .006 \\
Shoulder width $(s)$ & 0.171 & .050 \\
$\quad$ Lane width $\times$ shoulder width $(l s)$ & -0.128 & .093 \\
Dummy variables & & \\
Road type: $d_{r}$ & 0.385 & .000 \\
Driver 1 $\left(d_{d l}\right)$ & -0.038 & .182 \\
Driver 2 $\left(d_{d 2}\right)$ & -0.081 & .005 \\
Driver 3 $\left(d_{d 3}\right)$ & -0.049 & .090 \\
Driver 4 $\left(d_{d 4}\right)$ & 0.002 & .934 \\
Driver 5 $\left(d_{d 5}\right)$ & -0.349 & .000 \\
Driver 6 $\left(d_{d 6}\right)$ & -0.159 & .000 \\
Driver 7 $\left(d_{d 7}\right)$ & -0.159 & .000 \\
Driver 8 $\left(d_{d 8}\right)$ & -0.119 & .000 \\
Driver 9 $\left(d_{d 9}\right)$ & -0.075 & .009 \\
Driver 10 $\left(d_{d l 0}\right)$ & -0.133 & .000 \\
Driver 11 $\left(d_{d 11}\right)$ & -0.091 & .002 \\
Driver 12 $\left(d_{d 12}\right)$ & -0.135 & .000 \\
Driver 13 $\left(d_{d 13}\right)$ & -0.086 & .003 \\
Driver 14 $\left(d_{d 14}\right)$ & -0.122 & .000 \\
\hline
\end{tabular}

NoTE: Observation: $d_{d i}$ expresses the behavior of driver $i$ when compared with the base driver. $R=.89 ; R^{2}=.79$.
Table 7 shows that ordering the points of control of each road by speed results in the same sequence for both environments. Drivers tended to adopt higher speeds in the simulated environment than in the real environment. However, this result seems to reflect a translation of the absolute speed values that does not affect the conclusions of this study. Therefore, the results obtained with the DriS were considered to be valid, both in terms of relative and absolute speed differences.

Higher speeds were expected in the simulated environment because of the lack of grip effects and dynamic behavior of the car body. On N 222, the speed difference between both environments was approximately $40 \mathrm{~km} / \mathrm{h}$. On N 105-2, this value was reduced to approximately $30 \mathrm{~km} / \mathrm{h}$ because of the constraints imposed on drivers by the more demanding road alignment.

\section{CONCLUSIONS}

Previous studies have suggested that the width of road cross sections affect the free-flow speed chosen by drivers. The HCM (1) and the corresponding background study [NCHRP Project 3-55(3)] (2) take those effects into account by proposing values for speed reductions

TABLE 6 Reduction in Free-Flow Speed $(\mathrm{km} / \mathrm{h})$ According to Lane and Shoulder Widths

\begin{tabular}{|c|c|c|c|c|c|c|c|c|c|}
\hline \multirow{3}{*}{$\begin{array}{l}\text { Lane } \\
\text { Width (m) }\end{array}$} & \multicolumn{9}{|c|}{ Shoulder Width (m) } \\
\hline & \multicolumn{4}{|c|}{ N 105-2 } & \multicolumn{5}{|c|}{ N 222} \\
\hline & 0.3 & 0.8 & 1.2 & 1.8 & 0.3 & 0.8 & 1.2 & 1.8 & 2.2 \\
\hline 2.7 & 6.8 & 3.7 & 2.3 & 1.0 & 9.9 & 5.4 & 3.4 & 1.5 & 0.5 \\
\hline 3.0 & 4.6 & 2.3 & 1.4 & na & 6.7 & 3.4 & 2.1 & 0.7 & na \\
\hline 3.3 & 2.5 & 1.1 & 0.6 & na & 3.7 & 1.7 & 0.8 & na & na \\
\hline 3.6 & 0.6 & 0.0 & na & na & 0.9 & 0.0 & na & na & na \\
\hline
\end{tabular}

NotE: na $=$ not applicable. 
TABLE 7 Spot Speed Comparison of Real and Simulated Environments

\begin{tabular}{|c|c|c|c|c|c|c|c|}
\hline $\begin{array}{l}\text { Point of Control } \\
(R ; \text { Ext. })(\mathrm{m})\end{array}$ & $S S_{r}(\mathrm{~km} / \mathrm{h})$ & $S D_{r}(\mathrm{~km} / \mathrm{h})$ & $S S_{s}(\mathrm{~km} / \mathrm{h})$ & $S D_{s}(\mathrm{~km} / \mathrm{h})$ & $N_{r}$ & $N_{s}$ & $\begin{array}{l}S S_{s}-S S_{r} \\
(\mathrm{~km} / \mathrm{h})\end{array}$ \\
\hline \multicolumn{8}{|l|}{ N 105-2 } \\
\hline $\mathrm{I}(\infty ; 334)$ & 54.2 & 16.1 & 92.7 & 16.3 & 164 & 15 & 38.7 \\
\hline II $(150 ; 80)$ & 46.8 & 13.2 & 77.1 & 9.9 & 133 & 15 & 30.3 \\
\hline III $(\infty ; 473)$ & 76.3 & 18.6 & 98.6 & 11.2 & 112 & 15 & 23.6 \\
\hline \multicolumn{8}{|l|}{ N 222} \\
\hline $\mathrm{I}(545 ; 282)$ & 71.5 & 16.3 & 113.7 & 17.6 & 323 & 15 & 42.2 \\
\hline II $(\infty ; 240)$ & 76.9 & 16.8 & 119.4 & 20.3 & 325 & 15 & 42.4 \\
\hline III $(\infty ; 408)$ & 76.6 & 13.7 & 115.7 & 19.7 & 330 & 15 & 38.7 \\
\hline
\end{tabular}

NotE: $R=$ radius; ext. $=$ extension.

caused by different lane and shoulder widths. This study also confirmed the effects of the road cross section on the free-flow speed; this confirmation is emphasized by the significance of lane and shoulder width revealed in the multivariate analysis.

However, the obtained results differ from the HCM (1) proposals on three main points. The base cross section, defined as the minimum combination of lane and shoulder widths above which a decrease in the free-flow speed is no longer observed, is formed by a lane $3.6 \mathrm{~m}$ wide and a shoulder $0.8 \mathrm{~m}$ wide instead of a lane $3.6 \mathrm{~m}$ wide and a shoulder $1.8 \mathrm{~m}$ wide, as proposed by the HCM (1). Consequently, the speed reductions determined for smaller cross sections also differed from the HCM (1). However, the obtained speed reduction for the narrowest cross section (a lane of $2.7 \mathrm{~m}$ and shoulder of $0.3 \mathrm{~m}$ ) was approximately $10 \mathrm{~km} / \mathrm{h}$, which is close to the same value as that proposed by the HCM (1). Finally, an interaction between the effects of lane and shoulder width on free-flow speed was revealed, and they are not cumulative. Therefore, a simultaneous decrease in lane and shoulder widths produces a greater reduction in the free-flow speed than the sum of the same effects taken individually. This conclusion may contribute to a review of the lack of evidence assumed in the NCHRP Project 3-55(3) (2) for the existence of such interaction.

Despite being a widely adopted reference manual, the HCM (1) was developed for North American conditions, and its applicability to road networks with different geometric and environmental characteristics (e.g., roads in Portugal or other European countries) should be carefully considered.

From a comparison of the two considered roads, it is possible to conclude that the influence of a cross section on the free-flow speed also depends on the order of magnitude of the driving speeds.

The validity of the results obtained in the simulated environment confirms that driving simulators are reliable and flexible tools that may be used to create and study realistic traffic situations.

\section{ACKNOWLEDGMENT}

This study was conducted through the SAFESPEED project, financed by the Portuguese Science and Technology Foundation.

\section{REFERENCES}

1. Highway Capacity Manual 2010. Transportation Research Board of the National Academies, Washington, D.C., 2010.

2. Harwood, D. W., A. D. May, I. B. Anderson, L. Leiman, and A. R. Archilla. Capacity and Quality of Service of Two-Lane Highways. Final report, NCHRP Project 3-55(3). TRB, National Research Council, Washington, D.C., 1999.

3. Lobo, A., M. A. P. Jacques, C. M. Rodrigues, and A. Couto. Free-Gap Evaluation for Two-Lane Rural Highways. In Transportation Research Record: Journal of the Transportation Research Board, No. 2223, Transportation Research Board of the National Academies, Washington, D.C., 2011, pp. 9-17.

4. Speed Choice: The Influence of Man, Vehicle, and Road. Institute for Road Safety Research, Leidschendam, Netherlands, 2008.

5. Safety Evaluation of Lane and Shoulder Width Combinations on Rural, Two-Lane Undivided Roads. Publication FHWA-HRT-09-032. FHWA, U.S. Department of Transportation, 2009.

6. Bella, F. Operating-Speed-Predicting Models on Two-Lane Rural Roads from Driving Simulation. Presented at 84th Annual Meeting of the Transportation Research Board, Washington, D.C., 2005.

7. Bella, F. Driving Simulator for Speed Research on Two-Lane Rural Roads. Accident Analysis and Prevention, Vol. 40, No. 3, 2008, pp. 1078-1087.

8. Greene, W. H. Limdep Version 7.0 User's Manual, rev. ed. Econometric Software Inc., Plainview, N.Y., 1998.

9. Cohen, J. Statistical Power Analysis for the Behavioral Sciences, 2nd ed. Lawrence Erlbaum Associates Inc., Hillsdale, N.J., 1988.

The Operational Effects of Geometrics Committee peer-reviewed this paper. 